$\begin{array}{ll} & \text { Etnográfica } \\ \text { etnográfica } & \text { Revista do Centro em Rede de Investigação em }\end{array}$

Antropologia

vol. 11 (1) | 2007

Vol. $11(1)$

\title{
Maria Antónia Pires de Almeida, A Revolução no Alentejo: Memória e Traumas da Reforma Agrária em Avis
}

\section{Paula Godinho}

\section{OpenEdition}

Journals

\section{Edição electrónica}

URL: https://journals.openedition.org/etnografica/1966

DOI: 10.4000/etnografica.1966

ISSN: 2182-2891

\section{Editora}

Centro em Rede de Investigação em Antropologia

\section{Edição impressa}

Data de publição: 1 maio 2007

Paginação: 275-280

ISBN: 0873-6561; E-ISBN 2182-2891

ISSN: 0873-6561

\section{Refêrencia eletrónica}

Paula Godinho, «Maria Antónia Pires de Almeida, A Revolução no Alentejo: Memória e Traumas da Reforma Agrária em Avis», Etnográfica [Online], vol. 11 (1) | 2007, posto online no dia 26 setembro 2012, consultado o 12 fevereiro 2022. URL: http://journals.openedition.org/etnografica/1966 ; DOI: https:// doi.org/10.4000/etnografica.1966

\section{Este documento foi criado de forma automática no dia 12 fevereiro 2022.}

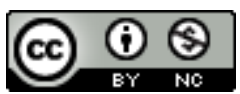

Etnográfica is licensed under a Creative Commons Attribution-NonCommercial 4.0 International License. 


\title{
Maria Antónia Pires de Almeida, A Revolução no Alentejo: Memória e Traumas da Reforma Agrária em Avis
}

\author{
Paula Godinho
}

\section{REFERÊNCIA}

Maria Antónia Pires de Almeida, A Revolução no Alentejo: Memória e Traumas da Reforma Agrária em Avis, Lisboa, ICS, 2006, 347 páginas.

1 Nesta adaptação duma tese de doutoramento em História Moderna e Contemporânea no ISCTE, pretende-se analisar a reforma agrária portuguesa em Avis, onde assumiu "proporções elevadíssimas", ainda que esteja por fazer a comparação por concelho e por distrito. Com "uma abordagem científica" (p. 20), interroga "o que levou uma população que viveu e trabalhou durante várias gerações com a cabeça baixa, os olhos no chão e o chapéu na mão de repente a levantar a cabeça e agir?” (p. 19). Maria Antónia Pires de Almeida, apresentada como "especializada em História Social Contemporânea e interessada na História Oral, Memórias e Identidades, Sociologia Rural e Património", considera que houve uma "direcção partidária", um "líder forte" e um "aparelho partidário" que encaminharam um movimento que não se justificava, porque "o tipo de vantagens adquiridas com a reforma agrária pelos trabalhadores propriamente ditos não me parece inovador em relação aos direitos já conquistados com as lutas no Verão de 1962 e a legislação emitida no governo de Marcelo Caetano" (p. 23). o processo de reforma agrária terá constituído um anacronismo por "as condições sociais e económicas nos campos já terem sofrido uma evolução positiva muito significativa precisamente devido à saída do excesso demográfico que pesava sobre aos campos e à legislação emitida no período de Marcelo Caetano" (p. 63). Assim, "interrompeu os processos de investimento na agricultura que estavam a ser postos em prática desde os anos 60 pelos mais dinâmicos empresários agrícolas alentejanos, sendo responsável por grande parte do desinteresse que actualmente se verifica no meio rural 
no que diz respeito a investimentos a longo prazo e projectos concretos de desenvolvimento empresarial" (p. 288), e cortou "qualquer tipo de contacto que existia entre os dois grupos mais significativos, quando antes ainda havia relações de trabalho e do patrocinato. As vilas e as aldeias dividiram-se, os ódios foram atiçados” (p. 289). Em virtude da "propaganda", deu-se uma transmutação dum "povo tradicionalmente submisso e de cabeça baixa numa turba violenta e cheia de coragem" (p. 148), que se divertia em "passeatas" (p. 225) "num ambiente festivo, com viagens à borla em camionetas para assistir aos comícios, a jorna paga pelo sindicato e a afirmação imparável de que se vivia em liberdade e já não havia patrões" (p. 149). As mulheres passaram a sair à rua sem ser exclusivamente para trabalhar, "com uma euforia de prisioneiras libertadas" (p. 149). Tornam-se "as primeiras nas manifestações e as que mais barulho faziam, mas no tipo de trabalho que realizavam a sua situação não mudou: continuaram agachadas a apanhar legumes e tomates, enquanto os homens conduziam tractores e ceifeiras-debulhadoras..." (p. 217)

2 A obra é dividida em sete capítulos. O primeiro centra-se na "questão agrária", com uma "análise histórica, bibliográfica e literária" (p. 21). O segundo é de carácter contextual, com o enquadramento local e regional de Avis entre meados do séc. XX e o 25 de Abril. Os capítulos III, IV e V debruçam-se sobre a "fase dramática da vida nacional" (p. 23) entre 1974 e 1977, com uma cronologia e legislação do processo de reforma agrária em Portugal, as instituições locais, o 25 de Abril e a reforma agrária em Avis. Estes anos, em que, segundo a autora, alguns autores estrangeiros (Nancy Bermeo, Jochen Bustorff ou Michel Drain, entre outros) "ajudaram a difundir uma certa visão utópica do processo de reforma agrária que agora se contesta" (p. 24), finalizariam com o "encerramento do período da crise de Estado" (p. 24), tratando o sexto capítulo a contrareforma agrária e a integração europeia, enquanto o último se centra na actualidade, nos "novos desafios".

3 Se o Sul rural da Península Ibérica foi longamente caracterizado na etnografia pela sua repartição em classes, com um grupo possidente claramente estabelecido no topo da escala social e uma mole de trabalhadores sem terra, "neste trabalho a grande dificuldade foi encontrar uma classe" (p. 14), ainda que noutro local afirme ter-se confrontado no concelho de Avis com baixas percentagens de proprietários e rendeiros e altas percentagens de trabalhadores rurais (p. 88). A reforma agrária teria sido destinada a beneficiar o grupo dos trabalhadores rurais e não o dos camponeses, que segundo a autora é constituído por proprietários, rendeiros ou parceiros (p. 62): “A classificação profissional de trabalhador passou nesta época a englobar uma série de categorias perfeitamente distintas e que variaram entre o feitor e todos os criados justos da grande lavoura até chegar aos mais eventuais dos trabalhadores alentejanos, contratados tanto à jorna como à tarefa" (p. 62). Obscurecendo a distinção entre a divisão técnica e a divisão social do trabalho, insiste na "maior diversidade social" (p. 77) que se pode detectar no Alentejo, já que "quando se pretendeu mobilizar a população rural para a reforma agrária, se verificou uma tentativa fortíssima de anulação intencional dessa diversidade e de reconstrução dos trabalhadores como um grupo coeso e igualitário" (p. 77). Reconhece que os locais de sociabilidade de classe eram diferenciados e que "uma característica unia de facto o grupo dos pobres: a imagem que faziam dos ricos" (p. 132), ainda que o aspecto destes nem fosse "muito ostensivo" e as suas mulheres deixassem "os casacos de peles nas arcas de cânfora (ou nos guarda-vestidos com naftalina) e as jóias no cofre, usando-os apenas em visitas 
esporádicas à capital ou em alguma ocasião social ou familiar festiva" (p. 132). Parecelhe que "é necessário desmistificar um pouco as ideias preconcebidas sobre as elites fundiárias alentejanas" (p. 134) e admira-se porque "em regra, os trabalhadores odiavam os grandes proprietários!" (p. 133). Questiona o absentismo, um "lugar comum" (p. 38), já que se uns proprietários viviam em Lisboa, outros ficavam-se pelos concelhos limítrofes, arrendando as suas explorações, e mesmo uma nova categoria, a das "senhoras com falta de preparação e incapazes de assumir a administração duma casa agrícola", que viviam "de rendas por incapacidade de se dedicarem à lavoura" (p. 203). "Na necessidade de 'viverem dos rendimentos', tinham o bom senso de arrendarem as terras a quem tinha maior competência para as cultivar" (p. 134). Assim, interroga-se: "Será isto absentismo?" (p. 135), já que alguns, "abnegadamente, tiveram mesmo que abandonar as suas profissões na capital para tomarem conta das 'lavouras' quando os pais ou padrinhos faleceram" (p. 137). Considera que houve uma intenção de bipolarizar o Alentejo nos autores neo-realistas ao longo do século $\mathrm{XX}$, através dos "estereótipos do latifundiário, cidadão 'de lavoura e cabaré', com uma conotação irremediavelmente negativa, e do trabalhador rural vitimado pelo próprio nascimento e pela condição de pobre, sem qualquer capacidade de escapar a um destino de servidão e de humilhação às mãos da prepotência do patrão e dos seus representantes: feitores, capatazes..." (p. 76). Mais, nenhum dos entrevistados lhe contou que "tivesse passado fome propriamente dita" (p. 120), e custa-lhe compreender que a seguir ao 25 de Abril, "Se para alguns o clima era de terror, para outros era de euforia. Grande parte da população do concelho viveu aqueles tempos em festa, com grandes banquetes, onde chegaram a ser comidos os veados da Fundação [Abreu Callado] e os touros reprodutores." (p. 203)

4 Considera que "as precárias condições culturais dos trabalhadores rurais de Avis foram aproveitadas por uma certa elite devidamente endoutrinada para o efeito pelo Partido Comunista Português, por via dos seus dirigentes sindicais na região" (p. 210), ou seja, os trabalhadores teriam visto acenarem-lhes com a possibilidade de "ser patrão, não trabalhar, ficar rico" (p. 211). Imediatamente a seguir ao 25 de Abril, "começaram a movimentar-se, assistiram a comícios e organizaram comissões para tudo e mais alguma coisa" (p. 182). o penúltimo presidente da Câmara terá sido expulso da vila, “juntamente com o vice-presidente que 'caiu na asneira' de declarar que tinha trabalhado para a PIDE (tratando os presos)" (183), numa ocasião em que "o povo tomou literalmente o poder nas suas mãos": a comissão administrativa da Câmara, com um vogal "operário agrícola", foi presidida por um enfermeiro filho de trabalhadores rurais "que tirou o curso na tropa e que na portaria de nomeação é referido como 'exodontologista»' (p. 185). Quanto ao reconhecimento do novo grupo de protagonistas da política local, admira-se com a assunção duma designação unificadora: "Como contraponto simbólico, é de acrescentar uma curiosidade, sem dúvida anedótica: cada um dos nomes escritos na acta da primeira reunião da comissão administrativa está precedido de 'senhor', por extenso, o que não deixa de ser significativo de um desejo de afirmação social por parte de um grupo que nunca antes tinha tido esse tipo de tratamento!" (p. 185) Espanta-a também que os novos dirigentes dos órgãos autárquicos passassem a ser eleitos por critérios como "a proximidade com os eleitores".

5 O processo de reforma agrária "Foi a altura ideal para forjar uma consciência de classe que nunca tinha existido e activar os recursos humanos para a mobilização social. Potenciando antigas frustrações e ressentimentos, a propaganda facilmente virou a multidão contra os antigos elementos do poder e conseguiu reverter e abolir 
completamente algumas solidariedades anteriormente existentes entre as classes." (p. 150) Tal foi possível por se tratar dum "grupo altamente sugestionável", já que "aos trabalhadores rurais faltava a capacidade crítica para interpretarem a situação que se lhes colocava, o que tem a ver com as circunstâncias culturais descritas e que se podem resumir no elevado grau de analfabetismo e em vidas de muito trabalho físico sem qualquer possibilidade de estímulo mental" (p. 152). Salienta a decepção de alguns trabalhadores rurais que "ainda hoje dizem que querem matar os ilusionistas que os 'levaram' para a reforma agrária", o que evidencia "o individualismo que marca este grupo e a pouca ou nenhuma importância dada a qualquer processo colectivo" e a "total falta de interiorização dos conceitos que presidiram, pelo menos em teoria, ao movimento", já que "o que cada um queria era a independência de um patrão e de uma renda de casa" (p. 260). Os trabalhadores reagiram "irracionalmente a um estímulo", vindo a constituir-se como "bando organizado e armado que actuou com a legitimidade revolucionária de quem quer mudar as normas culturais vigentes" (p. 184). Quanto aos proprietários, o processo ter-lhes-á "provocado sérias dificuldades económicas" (p. 153). Uma proprietária "chegou a vender os cordões de ouro da família para pagar as jornas" e começou a ver as suas roupas serem usadas por outras pessoas, sem poder reagir (p. 204). Mais: "As vítimas das ocupações de terras tiveram os seus percursos de vida definitivamente alterados e as suas relações com a propriedade agrícola e com o meio social em que estavam inseridos nunca mais voltaram a ser as mesmas." (p. 226)

Criadas as condições por parte do Governo, do IRA, do exército, "de que mais precisavam os trabalhadores para avançarem? Sobretudo quando a GNR parecia anestesiada." (pp. 155-6) E foi assim que "Neste final de 1974 os trabalhadores experimentaram algo que nunca haviam ousado e ninguém os reprimiu, pelo contrário" (156), um movimento que "corresponde ao da revolução bolchevique" (p. 165). o registo caricatural prossegue quando refere a participação da Escola Prática de Artilharia de Vendas Novas, cuja "brigada saía do quartel com grande aparato de jipes, chaimites e outros carros de combate, armada até às orelhas e com cabelos e barbas compridos, de 'aspecto alucinado', para se juntar a grupos de ocupantes e marcar a sua presença no terreno" (p. 164). Colando-se ao discurso dos proprietários, que toma acriticamente como seu, refere o aparelho legal então surgido, nomeadamente a "lei Oliveira Baptista", que conduziu à "peregrinação (muitos chamam calvário) dos proprietários a tentarem reaver as suas terras ocupadas e a pedirem as reservas a que tinham direito" (p. 169). “Em Avis foi a razia total!" (p. 200), tendo os proprietários salientado a "vingança, inveja e cobiça. Alguns trabalhadores queriam simplesmente ver os ricos a trabalhar como eles." (p. 200) A perspectiva dos proprietários é seguida com ardente fervor, mostrando a autora certezas inabaláveis no que lhe contaram: "Se houve descapitalização das explorações agrícolas, esta não resultou de qualquer tipo de sabotagem económica ou desinvestimento. Pelo contrário, foi provocada pelas despesas extraordinárias a que as colocações obrigatórias de pessoal e o impedimento da venda de gado obrigavam." (p. 202) Quanto à contra-reforma agrária, os que ficaram no desemprego aquando da entrega das herdades "a longo prazo grande parte deles até acolheu com satisfação o afastamento definitivo da actividade agrícola, pois tratava-se de uma população rural a caminhar para o envelhecimento e as novas gerações tinham outras habilitações e outros interesses profissionais que as atraíam para outros sectores de actividade ou mesmo para outras regiões ou países" (p. 250). Nos anos de 1978 a 1980, com as desocupações, destaca-se o papel dos filhos dos proprietários: "nas datas marcadas para as entregas reuniam-se irmãos, primos e amigos que se entrincheiravam 
nos montes (...) As desocupações constituíram assim um período de autêntica euforia, com a excitação típica dos jovens, sem excepção do sexo masculino, que pela primeira vez tiveram autorização e até apoio dos pais para saírem em grupo e armados quase para uma batalha campal, devidamente abastecidos com farnel e muita bebida." (p. 253) A autora comove-se: "Podemos imaginar o medo, misturado com orgulho, das respectivas famílias. Os meninos estavam a recuperar as nossas terras aos comunistas!” (p. 253)

$7 \mathrm{Na}$ actualidade, o espaço rural refuncionalizou-se, em função do turismo e do artesanato, com a paisagem e a natureza a tornarem-se visitáveis. Os turistas adoptam um comportamento com similitudes aos dos filhos dos proprietários que "praticam os desportos mais adequados ao grupo social em que estão inseridos: equitação, alta escola e tauromaquia, alguns pertencem a grupos de forcados, quase todos possuem jet-skis, quads, fazem motocross, passeios de jipe em preparação para raids todo o terreno, caçam..., ao contrário dos pais, que, 'no seu tempo', nem à caça podiam ir porque tinham as herdades ocupadas... Mas não dispensam as 'outras' férias no Algarve de Verão e nos Alpes para os desportos de Inverno." (p. 283) A Câmara Municipal, que teve de suprir necessidades básicas por satisfazer e construir equipamentos sociais variados, lançou "infra-estruturas para um turismo que gera muito poucos resultados económicos, como foi o caso do parque de campismo" (p. 284). Deixando antever que as vedações actuais dos terrenos, sobretudo de caça, impedem a circulação e o acesso a locais de interesse geral, adianta que quem procurar os dólmenes e menires do concelho, não os encontra, já que "muitos deles estão dentro de herdades vedadas e sem estradas ou caminhos de acesso" (p. 284).

8 A autora considera ter usado "métodos de trabalho rigorosos aprendidos com a sociologia, a antropologia e a ciência política" (p. 15), realizando entrevistas, que constituem "a base da análise e um importante factor de originalidade" (p. 15), através das quais pretende "Dar a voz aos intervenientes de forma rigorosa e (o mais possível) isenta" (p. 15). Quanto à pretensão à isenção, na obra os trabalhadores rurais são referidos por alcunhas (Cuco, Sarrafaça, Mascote) e os proprietários pelos títulos académicos (A Sra. Engenheira, na p. 204). Ainda que a autora tenha escrito que manteve o sotaque nas transcrições, "e mesmo algumas incorrecções ortográficas e gramaticais utilizadas pelos entrevistados, o que teve a intenção de valorizar a riqueza da linguagem regional e de modo nenhum é usado de forma depreciativa" (p. 25, em nota), o título dum sub-capítulo, 'Os hipotenizados' e outras referências ao correr do texto (Bertolameu, na p. 196) denunciam um significativo desrespeito por alguns dos que acederam a falar-lhe, a que aplica o ferrete de classe e um paternalismo inaceitável num estudo de ciências sociais, bem evidenciado na citação duma proprietária, escolhida para epígrafe da conclusão. Enquadra alguns comportamentos numa espécie de personalidade-base do Sul: "Basicamente, os alentejanos e as populações mediterrânicas, em geral, não têm, por uma questão de mentalidade, o hábito ou qualquer vontade de se exporem em público" (p. 218), sem entender que há conjunturas revolucionárias e que a psicologia colectiva é uma fraca explicação, como fica demonstrado quando contesta Nancy Bermeo (p. 26) ou quando naturaliza a "mentalidade da população em causa", porque "o alentejano emigra menos, tem uma ligação mais forte à terra e uma desconfiança natural em relação aos estranhos; mesmo que tenha algo a dizer, certamente não o fará em público e muito menos respondendo a um questionário" (p. 26). 
9 A falta de rigor da obra, que ignora estudos das elites na antropologia portuguesa e em que a perspectiva comparativa em torno dos movimentos rurais no mundo está completamente ausente, fica bem evidenciada na nota da p. 149, quando a autora resolve informar os leitores do que significa a sigla "MRPP": "Movimento Reorganizativo do Partido do Proletariado, vulgo Meninos Rabinos que Pintam Paredes". A utilização recorrente de maiúsculas (ROUBO, na p. 259), exclamações e reticências conduzem-na a um texto que se torna panfletário e parcial, que se conjuga com uma atitude paternalista quanto aos trabalhadores, mostrando-se incapaz de os entender como seres da história, com capacidade para escolher em função de constrangimentos, e condu-la a encará-los como manipuláveis, iludidos por outros, que os levaram a agir além da sua vontade. Tem toda a razão uma vez, quando classifica a sua obra: "não passa de um retrato, com todas as limitações impostas pela subjectividade da observadora." (p. 20)

\section{AUTORES}

\section{PAULA GODINHO}

Departamento de Antropologia, FCSH-UNL 